\title{
ДИНАМИКА БРАЧНОСТИ В РЕСПУБЛИКЕ МОЛДОВА ЗА 2014-2020 гг. ${ }^{1}$
}

\author{
Ana Chivaciuc@2 ${ }^{2}$, научный сотрудник \\ Центр Демографических исследований, \\ Национальный Институт Экономических Исследований, \\ Республика Молдова \\ DOI: https://doi.org/10.36004/nier.cdr.2021.15-22
}

\begin{abstract}
The article analyzes the changes in the marriage rate in Moldova over the study period. It was revealed that against the background of a general trend of gradual decline, a significant drop in the number of marriages was recorded in 2020, which is largely due to measures to counter the spread of the COVID-19 infection. Along with this, other factors are considered that have an adverse effect on the dynamics of marriages in the republic. The data on nuptiality in the territorial context, among men and women in different marriageable age groups, as well as the ratio of potential grooms and brides among Moldovan youth, are compared. The dynamics of marriage rates against the background of a general decline in the population and an unfavourable age-sex structure of young generations entering childbearing age is becoming one of the characteristics that explain the expected low fertility in the future.
\end{abstract}

Keywords: marriage, childbearing, demographyc decline

JEL Classification: J11

Институт брака и семьи является фундаментальной социальной основой процесса воспроизводства населения, поэтому важность рассмотрения брачности в динамике не только не утрачивает своей актуальности, но и обретает ряд особенностей на современном этапе развития. Заключение брака и образование новой семьи - это не только создание стартовых условий для рождения детей, с семьи начинается познание ребенком общественных норм, культурных ценностей, приобретаются знания и умения. Несмотря на комплексность и глобальный характер факторов, активно трансформирующих образ современной семьи, трудно переоценить её неизменно высокую значимость для сохранения и развития общества.

За последние несколько лет в жизнь каждого человека, в той или иной мере, вошло и укрепилось такое явление как «пандемия COVID-19», расширяясь поэтапно до настоящего момента времени. Становится всё более очевидно, что карантинные меры оказывают определенное влияние на все основные сферы деятельности человека, затронув, в том числе, и брачные отношения. Для большинства людей

\footnotetext{
${ }^{1}$ Статья разработана в процессе выполнения Государственной Программы (20202023) 20.80009.0807.21 Migrația, schimbări demografice și politici de stabilizare a situației / Миграция, демографические изменения и политики по стабилизации ситуации.

2 (C) Ana Chivaciuc, anna924kivachuk@mail.ru
} 
самоизоляция/реабилитация после перенесенного заболевания COVID19 протекают в узком кругу совместного проживания. Длительность этого процесса и высокая степень неопределенности создали условия для формирования беспрецедентного психологического давления, нарушив планы и привычный ход жизни людей, стабильность доходов и финансового положения. К таким жизненно важным планам в полной мере можно отнести заключение брачных союзов, опираясь на данные брачности в описываемый период (Рис. 1).

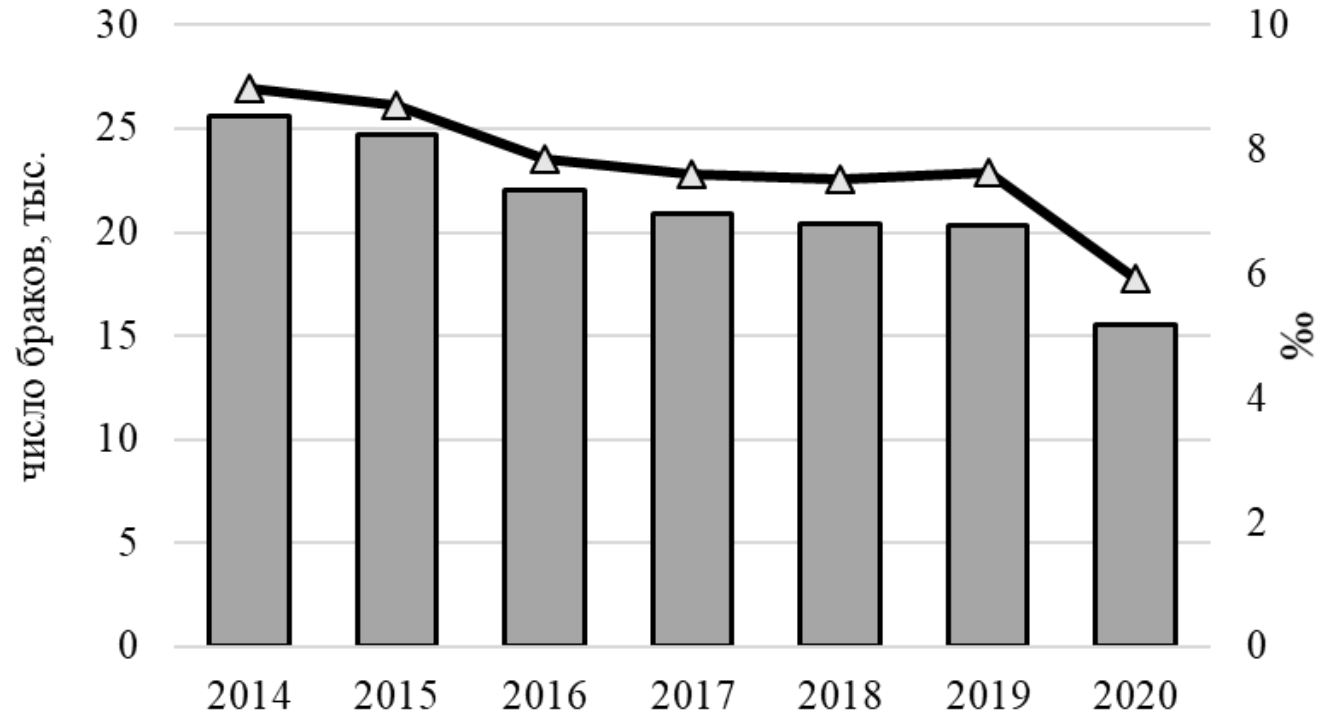

Рисунок 1. Динамика числа браков и общего коэффициента брачности, 2014-2020 гг.

Источник: данные Национального бюро статистики РМ.

В течение анализируемых 6 лет интенсивность заключения брачных союзов в Молдове постоянно, но не интенсивно снижалась, однако, с окончанием 2019г. ситуация заметно ухудшилась. В наступившем 2020 г. зафиксированы наименьшие показатели брачности за данный период, когда было заключено 15,5 тыс. браков, а общий коэффициент брачности составил 5,9 на 1000 населения. Наибольшее количество браков (25,6 тыс.) было зарегистрировано в 2014 г., при этом общий коэффициент брачности составил 9,0\%0. Подобное крушение показателей брачности было отмечено демографами Молдовы в 2000-2002 гг., когда общий коэффициент брачности составил 5,1-5,8 на 1000 населения. Отметим, что в тот период приведенные значения были отмечены, как самые низкие за период, начиная с 1950 г. (Палади, Г. А., Шахотько, П. П., Гагауз, О. Е., 2010). 
Очевидно, что современные особенности брачности формируются под влиянием факторов социально-экономического характера. Среди наиболее значимых неблагоприятных условий, способствовавших резкому изменению показателей брачности в 2020 г., можно выделить:

- установление длительных карантинных ограничений на проведение массовых мероприятий, к которым были отнесены свадебные торжества;

- снижение финансовых доходов населения на фоне вынужденных карантинных ограничений по занятости в реализации товаров и услуг;

- психологическую напряженность, возникшую из-за необходимости нахождения в течение длительного времени в замкнутом пространстве среди ограниченного числа совместно проживающих людей.

С одной стороны, были смещены ценностные ориентиры в оценке себя и близких людей в новых экстремальных условиях жизни. В условиях коронавирусной инфекции и «постковидного синдрома», сыгравших роль катализатора социально-экономических и психологических проблем в добрачных семейных отношениях, брак, как демографическая категория, в целом подвергся серьезному испытанию на прочность (Прокудина, Р. О., Лобода, П. Е., 2021).

На этом фоне, рассматривая самоизоляцию как стрессогенный фактор, повлекший изменения показателей брачности, можно отметить, что его роль опосредована и она лишь обострила то, что уже было накоплено негативного в отношениях между потенциальными брачными партнерами - сожительствующими женихами и невестами, планирующими вступить в брак, но до этого сглаживалось в силу высокой степени разобщенности молодых людей, их занятости на учебе и работе.

C другой стороны, часть молодежи, желающей не просто официально оформить свои отношения, а отпраздновать свадебное торжество, были вынуждены отсрочить его проведение до установления более благоприятных условий, дождавшись отмены карантинных запретов, ограничений в области международного перемещения людей и т.д. Немаловажно учитывать и материальную сторону отложенных бракосочетаний в анализируемый период, поскольку свадьба является дорогостоящим мероприятием, и для молодых людей, не обладающих собственными финансовыми накоплениями или достаточной поддержкой родителей, это стало решающим аргументом. Не следует при анализе данных игнорировать и тот факт, что на интенсивность заключения браков зачастую влияет их 
сезонный характер, связанный с культурными и религиозными традициями, возможностями осенне-летнего продуктового изобилия.

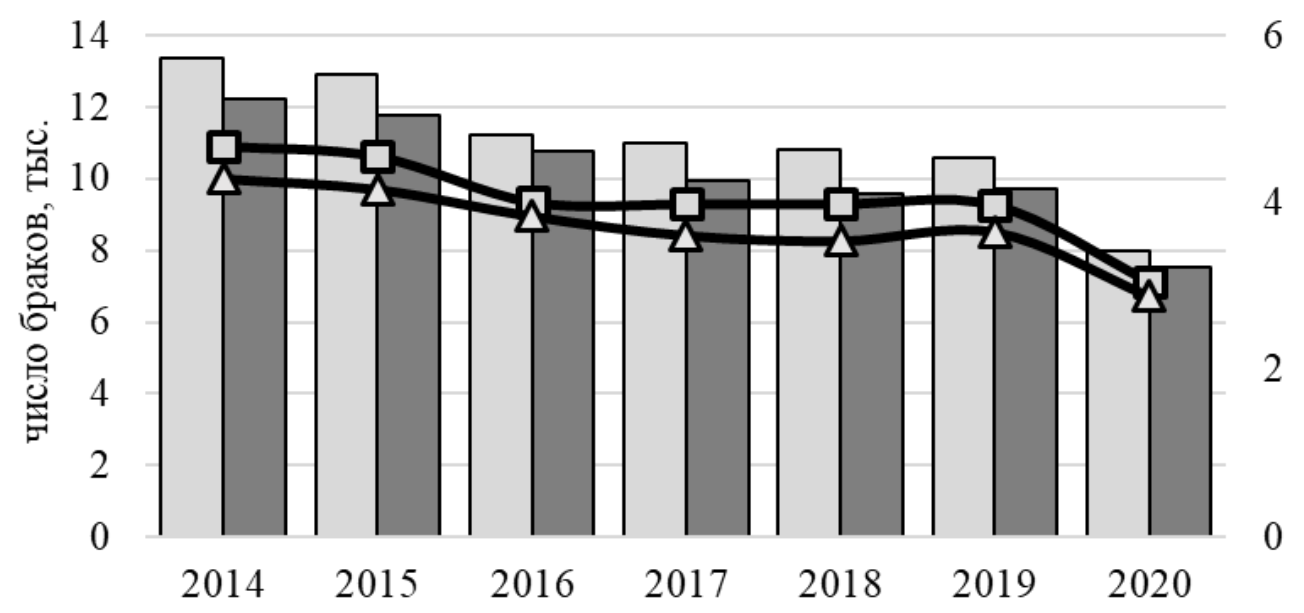

$\square$ город, тыс. $\square$ село, тыс. $\quad-\square$ город, \%о $\Delta-\boldsymbol{\Delta}$ село, \%о

Рисунок 2. Динамика числа браков и общего коэффициента брачности в территориальном разрезе, все население, 2014-2020 гг. Источник: данные Национального бюро статистики РМ

Отдельного рассмотрения заслуживают изменения в динамике числа браков и общего коэффициента брачности в зависимости от типа поселения (Рис. 2). Число браков неизменно снижается и в городе, и в сельской местности на протяжении всего рассматриваемого периода. Если в 2014 г. для горожан число браков составило13,4 тыс., то для сельчан этот показатель составил 12,3 тыс. браков, то уже в 2019 г. были зафиксированы данные 10,6 тыс. и 9,7 тыс. браков соответственно.

При этом резкое сокращение браков, в связи с принудительной и самоизоляцией из-за распространения коронавирусной инфекции в 2020 г., отразилось на населении всей республики. Тем не менее, именно в 2020 г. наблюдается максимальное сближение показателей общего коэффициента брачности между городом $(3,0 \% 0)$ и селом $(2,9 \% 0)$, составив разницу всего в $0,1 \%$, а в предшествующий период он в среднем за 5 лет составил $0,4 \%$. Кроме того, играет роль специфика половозрастной структуры населения и ее особенности в молодых возрастах, в значительной мере сформировавшиеся под воздействием миграционных процессов и особенности образа жизни молодежи в городе и селе. 


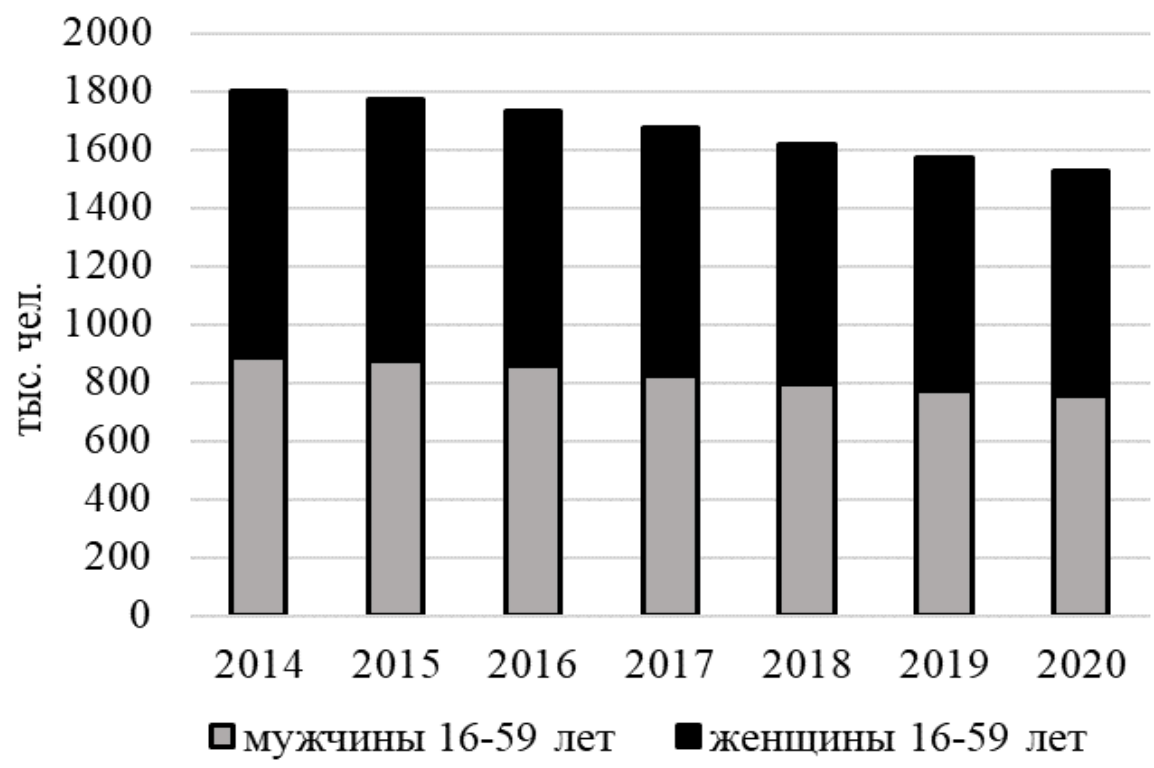

Рисунок 3. Среднегодовая численность населения в бракоспособном возрасте, мужчины и женщины, 2014-2020 гг.

Источник: данные Национального бюро статистики РМ.

Динамика числа браков в значительной степени зависит от тенденции в изменении численности бракоспособного контингента. Неблагоприятная возрастная структура населения бракоспособного возраста также способствует снижению общего числа браков, поскольку число мужчин и женщин в возрасте 20-29 лет объективно сокращалось за счёт относительно малочисленных поколений, рожденных в период 1990-2000 гг. (Рис. 3). Данные среднегодовой численности населения Молдовы в бракоспособном возрасте 16-59 лет среди мужчин и женщин демонстрируют неизменное снижение показателей с 1803 тыс. человек в 2014 г. до 1530 тыс. человек в 2020 г. 


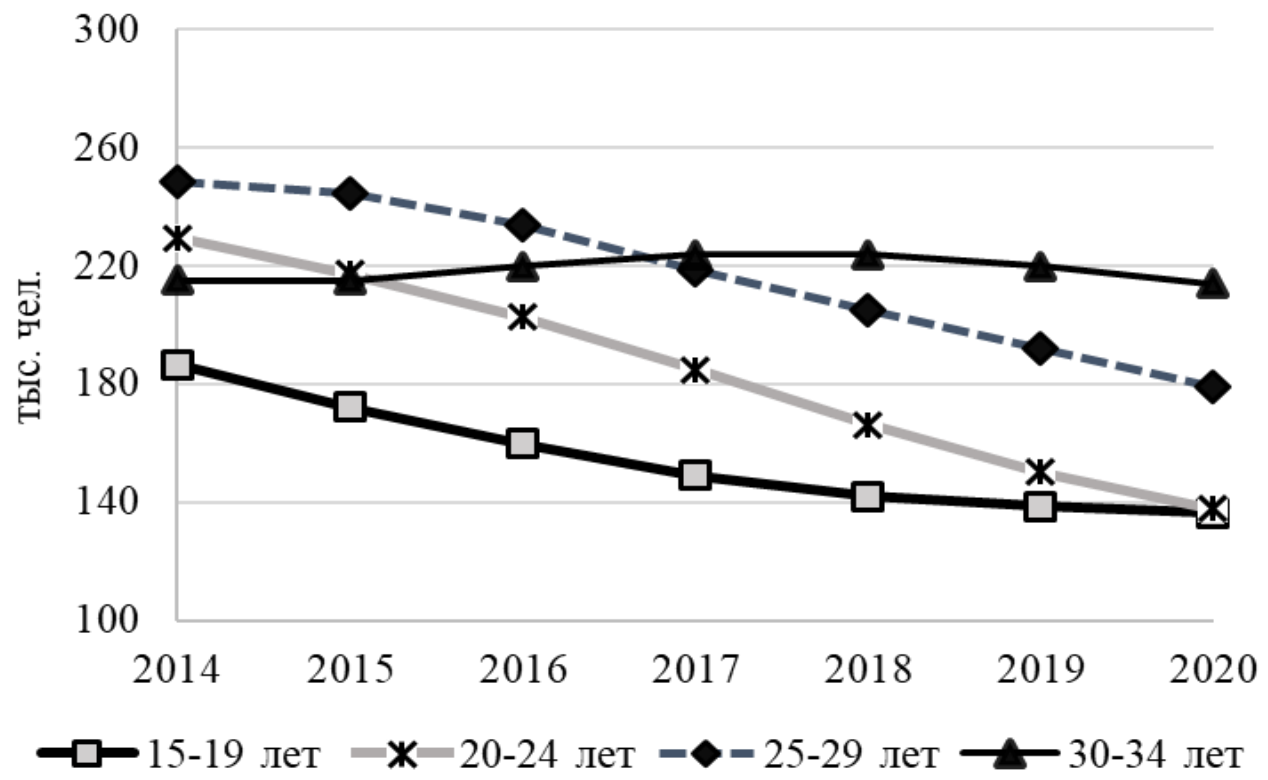

Рисунок 4. Среднегодовая численность населения обоих полов в соответствующих возрастах, все население, 2014-2020 гг.

Источник: данные Национального бюро статистики РМ.

В возрастах максимальной брачности суммарная численность населения снизилась на 160,6 тыс. человек (Рис. 4). Падение значений в самой молодой из представленных возрастных групп 15-19 лет сравнительно менее стремительно, составило 50,2 тыс. человек, что объясняется ростом числа браков и общим улучшением картины рождаемости в республике после 2005 г. Наименее значимые изменения произошли с 2014 по 2020 гг. в численности возрастной группы 3034 лет для обоих полов, данные варьируют в диапазоне 215-214 тыс. человек. 


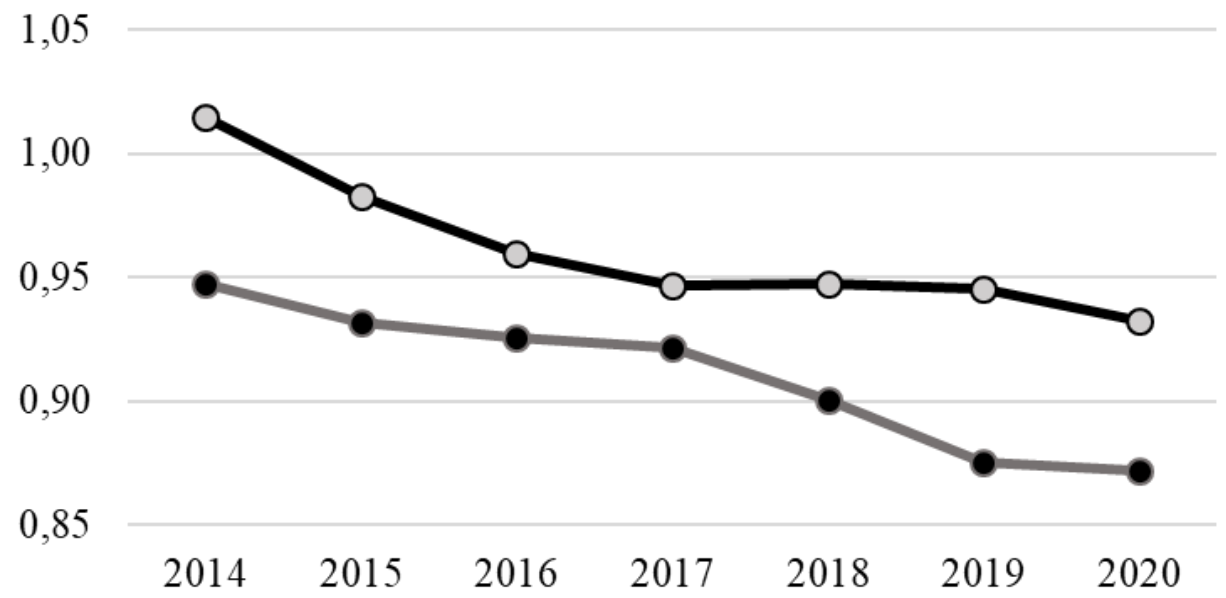

--мужчины 22-26 лет/женщины 20-24 лет

-

Рисунок 5. Соотношение потенциальных женихов и невест в возрастах максимальной брачности, число мужчин в возрасте 22-26 и 27-31 лет на одну женщину в возрасте 20-24 и 25-29 лет, 2014-2020 гг.

Источник: данные Национального бюро статистики РМ

Сопоставление количества потенциальных женихов и невест проведено в возрастах, наиболее привлекательных для заключения брака, при этом мужской контингент старше на 2 года, исходя из распространенных стандартов соотношения возраста женихов и невест (Рис. 5). В соответствии со статистическими данными, наиболее благоприятное соотношение, в период с 2014 по 2020 гг., складывалось в более старшей группе, где на одну потенциальную невесту приходится один потенциальный жених. Во второй группе, представители которой моложе на 5 лет, ситуация выглядит менее благоприятной: максимальное значение 0,95 в 2014 г. постепенно снижается до 0,9 в 2018 г. и затем достигает отметки 0,87 в 2020 г. 


\section{2}

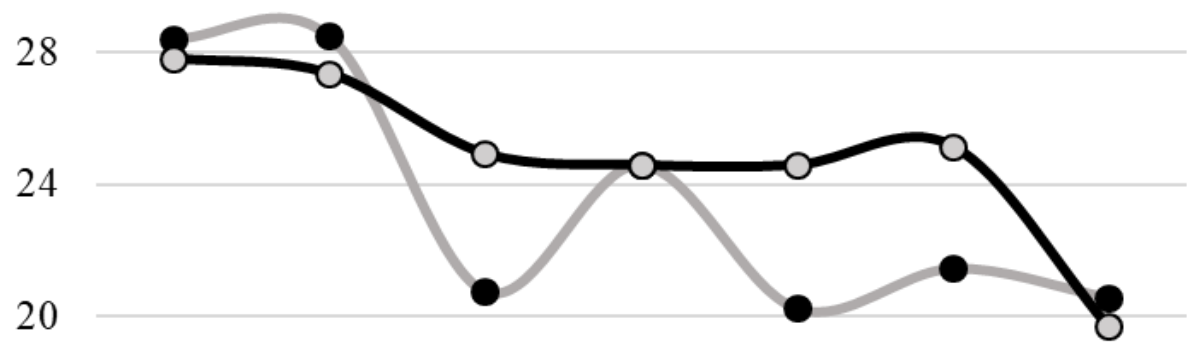

16

$\begin{array}{lllllll}2014 & 2015 & 2016 & 2017 & 2018 & 2019 & 2020 \\ \text { — мужчины, \%о } & \text { - } \text {-женшины, \%о }\end{array}$

Рисунок 6. Динамика специального коэффициента брачности для мужского и женского населения в бракоспособном возрасте 16-59 лет, 2014-2020 гг.

Источник: данные Национального бюро статистики РМ

Современные процессы, которые происходят в обществе, специфически отражаются на сфере брачно-семейных отношений: снижается уровень брачности, уменьшается численность населения в возрастах потенциальных женихов и невест, увеличивается возраст вступления в брак. Кроме того, происходит ломка традиционной брачной системы и распределения гендерных ролей в семье. Это связано с тенденцией к постепенной маскулинизации женщин, и одновременно распространением социальной модели мужчины «феминного» типа. Бесспорно, эти процессы оказывают пагубное влияние на брачное поведение, реализацию поло-ролевых функций в брачных отношениях, а также на формирование представлений о браке (Кучмаева, О. В., Ростовская, Т. К., 2020). За последние десятилетия значительно ослабло регулирующее воздействие ранее принятых и закрепленных в обществе норм брачно-семейного поведения. Следствием этого явились изменения в добрачном поведении молодежи - широкое распространение и социальное одобрение получил феномен сожительства, который постепенно обретает статус «обязательного этапа», предшествующего браку или даже полной его альтернативой.

\section{ЛИТЕРАТУРА}

Кучмаева, О. В., Ростовская, Т. К. (2020). Динамика брачности и разводимости в России. In А. В. Рязанцев С. В., Демографическое развитие России: тенденции, прогнозы, меры. Национальный демографический доклад (рр. 
23-25). Москва: 000 «Объединенная редакция» doi:10.25629/HC.2020.13.01

Палади, Г. А., Шахотько, П. П., Гагауз, О. Е. (2010). Основные вызовы демографической безопасности: сходства и различия в Молдове и Беларуси. Chișinău: I.E.P. Știița.

Прокудина, Р. О., Лобода, П. Е. (2021). Междисциплинарное исследование влияния пандемии covid-19 на институты семьи и брака. StudNet, Nr.4. 